\title{
Absolute lymphocyte count is a predictor of outcome after splenectomy for immune thrombocytopenia
}

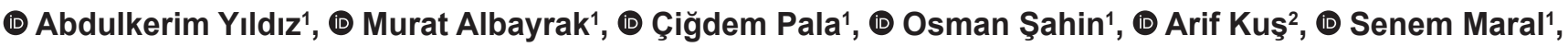 \\ (1) Pınar Cömert' ${ }^{1}$, (1) Hacer Berna Afacan Öztürk ${ }^{1}$
}

1 University of Health Sciences Turkey, Diskapi Yildirim Beyazit Training and Research Hospital, Department of Hematology, Ankara, Turkey

2University of Health Sciences Turkey, Diskapi Yildirim Beyazit Training and Research Hospital, Department of Internal Medicine, Ankara, Turkey

Date submitted:

25.10.2019

Date accepted:

20.11.2019

Online publication date:

15.06.2020

\section{Corresponding Author:}

Abdulkerim Yıldız MD, University of Health Sciences Turkey, Diskapi Yildirim Beyazit Training and Research Hospital, Department of Hematology, Ankara, Turkey

akerim@hotmail.com

ORCID:

orcid.org/0000-0002-9596-4042

Keywords: Splenectomy, immune thrombocytopenia, lymphocyte count, treatment outcome

\begin{abstract}
Aims: Splenectomy is still the standard salvage therapy in immune thrombocytopenia (ITP) cases refractory to corticosteroid therapy. The aim of this study was to evaluate adult ITP patients who underwent splenectomy and to analyze the predictive factors of response to splenectomy.

Methods: A retrospective analysis was performed from 2009 to 2018 using the data of 46 patients with ITP who underwent splenectomy in our hospital. The diagnosis and response to treatment were evaluated according to the International Working Group recommendations. A complete response (CR) was accepted as any platelet count $>100 \times 109 / \mathrm{L}$. A partial response (PR) was accepted as any platelet count from $30-100 \times 109 / \mathrm{L}$ or a doubling of basal platelet count.
\end{abstract}

Results: After splenectomy, 38/46 (82.7\%) patients achieved CR and 6/46 (13.0\%) achieved PR. Fifteen (34.0\%) responders relapsed with a median time of 61.9 months. Compared to the nonresponders and relapsed patients ( $N R+$ relapsed, $n=17)$, the stable responders $(C R+P R, n=29)$ had lower absolute lymphocyte count (ALC) $(A L C, \times 109 / \mathrm{L})$ at the time of diagnosis [1.8 (0.84-4.32) vs 2.47 (1.4-5.1); $p=0.018]$. Patients with $A L C \leq 1.85 \times 10^{9} / \mathrm{L}$ at the time of diagnosis had a better response to splenectomy to splenectomy than those with ALC $>1.85 \times 109 / L(p=0.031)$. According to the CoxRegression module, we demonstrated that the increase in initial ALC would increase the relapse rate after splenectomy (Hazard ratio: 1.003, 95\% confidence interval: 1.001-1.005; $p=0.009$ ).

Conclusions: Splenectomy is a safe treatment with a long-term CR rate of $58.6 \%$ for ITP patients. The findings highlighted that ALC at the time of diagnosis was the only predictive variable of long-term response to splenectomy in patients with ITP.

\section{Introduction}

Immune thrombocytopenia (ITP) is an autoimmune disease characterized by increased thrombocyte destruction and impaired thrombocyte production which can lead to isolated thrombocytopenia and spontaneous (1). The incidence of primary ITP in adults ranges between 1.6 and 3.9/100.000 people/year (2). With the development of new drugs such as thrombopoietin receptor agonists, splenectomy remains the second-line treatment for ITP patients unresponsive to corticosteroids $(1,3,4)$. The cure rate of splenectomy has been reported to be higher than that of other treatments, at $60-70 \%$ in 5 years (5). In addition, no clear international guidelines for the order of treatment of ITP have been proposed and the selection of treatment has been seen to be based on physician and patient preference rather than on the evidence of clinical experience (6).

The criteria and parameters that can predict response to splenectomy and prognosis are currently of great interest to researchers. The most frequently studied predictive and prognostic factors in splenectomy are age, the response to steroid treatment before splenectomy, the time from diagnosis to splenectomy (duration of disease), and pre-postoperative platelet count. There are conflicting results in different studies and no factor has been determined to consistently predict the 
response. Therefore, there is still a need for disease-specific parameters which can be used in clinical practice. The aim of this retrospective study was to evaluate adult ITP patients who underwent splenectomy in our hospital during the last 9 years and to analyze the predictive factors of response to splenectomy.

\section{Methods}

\section{Ethical approval and informed consent}

All procedures performed in the studies involving human participants were in accordance with the ethical standards of the institutional and/or national research committee and with the 1964 Helsinki Declaration and its later amendments or comparable ethical standards. The study was approved by University of Health Sciences Turkey, Ankara Diskapi Yildirim Beyazit Research and Training Hospital Ethics Committee (protocol no: 57/12, date: 17.12.2018).

A retrospective examination was performed from the records of patients diagnosed with ITP and followed up in the Hematology Clinic of University of Health Sciences Turkey, Diskapi Yildirim Beyazit Training and Research Hospital. A total of 46 patients who underwent splenectomy for therapeutic purposes were included. For all the patients examined, a record was made of demographic information, date of diagnosis, treatments received, responses to treatments, date of splenectomy, complete blood count follow-up after splenectomy and total follow-up period. Using these data, analysis was applied to response rates to splenectomy, relapse rates after splenectomy, and relapsefree survival (RFS) rates. Of the hematological parameters at the time of diagnosis, the effects of platelet count, absolute lymphocyte count (ALC), plateletcrit (PCT), platelet distribution width (PDW), mean platelet volume (MPV), platelet/lymphocyte ratio (PLR), lactate dehydrogenase (LDH), ferritin and vitamin B12 levels were examined on relapse rates and RFS rates after splenectomy.

The diagnosis of chronic ITP was based on the International Working Group (IWG) standard of a peripheral blood platelet count of $<100 \times 109 / \mathrm{L}$ continuing for more than 1 year after discounting other reasons of thrombocytopenia (7). The response to treatment to treatment was evaluated according to the IWG recommendations. A complete response (CR) was accepted as any platelet count $>100 \times 109 / \mathrm{L}$. A partial response $(P R)$ was accepted as any platelet count from $30-100 \times 109 / \mathrm{L}$ or a doubling of basal platelet count. No response (NR) was accepted as platelet count $<30 \times 109 / \mathrm{L}$ or an increase of less than double basal platelet count. Corticosteroid dependency is defined as platelet count maintained at a minimum of $30 \times 109 / \mathrm{L}$ and/or a need for continuous or repeated application of corticosteroids to prevent bleeding for a period of more than 2 months (7). To exclude other hematological diseases and evaluate megakaryocyte count, bone marrow biopsy was performed to all patients.

\section{Statistical Analysis}

Statistical analyses of the study data were made using SPSS Statistics 20 software (IBM, Armonk, NY, USA). Descriptive data were reported as number $(\mathrm{n})$ and percentage (\%). For survival analysis, the Kaplan-Meier method was used. RFS was calculated as the time from response obtained following splenectomy to the time of relapse. Comparisons between the patient groups were made using the Log-Rank test. In the comparison of 2 independent variables with measurement values with normal distribution, the Independent Samples t-test was used and if there was not normal distribution, the Mann-Whitney $U$ test (Z-table value) was employed. In the examination of the relationships between 2 qualitative variables, the chi-square cross tables were used according to the levels of the expected values. The optimal cut-off value was determined using the ROC curve analysis. A value of $p<0.05$ was accepted as statistically significant.

\section{Results}

The patient characteristics are presented in Table 1. Evaluation was performed on a total of 46 patients, comprising 31 (67.3\%) females and $15(32.7 \%)$ males with a mean age of $43.52 \pm 15.89$ years. Splenectomy was performed at a mean standard deviation (SD) patient age of 37.57 (17.25) years at a mean (SD) 41.93 (75.61) months after ITP diagnosis. Accessory spleen was determined in 4 patients relapsed after splenectomy and surgical removal was applied. All the patients were treated with corticosteroids at least once before splenectomy. Corticosteroid dependency was determined in $28(60.8 \%)$ and NR to corticosteroids was observed in $18(39.2 \%)$. The follow-up period after splenectomy was mean (SD) 60.70 (80.31) months. The mean (SD) total period from diagnosis to final follow-up was 102.62 (111.06) months.

The response to splenectomy was evaluated in 1 month postoperatively and at the final follow-up examination. In 1 month after splenectomy, a response was obtained in 44 of 46 patients (95.6\%) as CR in 38 and PR in 6 patients, and NR was

\begin{tabular}{ll}
\hline \multicolumn{2}{|l|}{ Table 1. General characteristics of the patients } \\
\hline Variable ( $\mathbf{n = 4 6 )}$ & \\
\hline $\begin{array}{l}\text { Gender } \\
\text { Female } \\
\text { Male }\end{array}$ & $31(67.4 \%)$ \\
\hline Age at diagnosis (yrs) (Mean \pm SD) & $34.00 \pm 19.43$ \\
\hline Current age (yrs) (Mean \pm SD) & $43.54 \pm 15.89$ \\
\hline Age at splenectomy (yrs) (Mean \pm SD) & $37.57 \pm 17.25$ \\
\hline $\begin{array}{l}\text { Time from diagnosis to splenectomy } \\
\text { (months) (Mean } \pm \text { SD) }\end{array}$ & $41.93 \pm 75.61$ \\
\hline $\begin{array}{l}\text { Time from splenectomy to last follow-up } \\
\text { (months) (Mean } \pm \text { SD) }\end{array}$ & $60.70 \pm 80.31$ \\
\hline $\begin{array}{l}\text { Time from diagnosis to last follow-up } \\
\text { (months) (Mean } \pm \text { SD) }\end{array}$ & $102.63 \pm 111.06$ \\
\hline Yrs: Years, SD: Standard deviation & \\
\hline
\end{tabular}


obtained in $2(4.4 \%)$ patients. Relapse occurred during follow-up in a total of 15 patients as 4 with PR and 11 with CR. The time to relapse was median 61.9 months. In the 4 relapsed patients with prior PR, the relapse occurred within first 1 year. In the total follow-up period, 27 patients had CR; therefore, the long-term response rate of splenectomy was determined as 58.6\% (27/46) (Table 2).

The total 17 patients including 2 patients with NR to splenectomy and 15 patients relapsed after splenectomy compared to the 29 patients with a stable response ( $C R+P R)$ who received no treatment and had no relapse throughout the follow-up period. No statistically significant difference was determined between the groups in respect of age, gender, response to steroids before splenectomy, immunosuppressive drug usage, comorbidities, time from diagnosis to splenectomy (months), age at splenectomy

\begin{tabular}{|lll|}
\hline Table 2. Response rates to splenectomy & \\
\hline $\begin{array}{l}\text { 1 month after } \\
\text { splenectomy }\end{array}$ & $\begin{array}{l}\text { Long-term } \\
\text { follow-up }\end{array}$ \\
\hline Complete response & $38 / 46(82.7 \%)$ & $27 / 46(58.6 \%)$ \\
\hline Partial response & $6 / 46(13.0 \%)$ & $2 / 46(4.3 \%)$ \\
\hline No response & $2 / 46(4.3 \%)$ & $2 / 46(4.3 \%)$ \\
\hline Recurrence & - & $15 / 44(34.1 \%)$ \\
\hline
\end{tabular}

(years), platelet count, and PCT, MPV, PLR, PDW, LDH, vitamin B12 and ferritin levels $(p>0.05)$. ALC in patients with a stable response was determined to be significantly lower than that of patients with NR or subsequent relapse $(p=0.018)$ (Table 3). The optimal ALC cut-off value was determined as 1.85 with $86.7 \%$ sensitivity and $51.7 \%$ specificity (AUC=0.717; $p<0.05)$. Patients with $\mathrm{ALC} \leq 1.85 \times 109 / \mathrm{L}$ at the time of diagnosis were determined to have a better response to splenectomy than those with ALC $>1.85 \times 109 / \mathrm{L}(\mathrm{p}=0.031)$ (Table 4).

To identify the determinants of a permanent response to splenectomy, RFS analysis was applied to a total of 44 patients with $\mathrm{CR}$ and PR after splenectomy. The 1, 3, and 5-year RFS rates after splenectomy were determined as $90.9 \%, 86.3 \%$ and $84.0 \%$, respectively. As a result of the Cox-Regression model applied according to the response to splenectomy, ALC at the time of diagnosis was seen to have a statistically significant effect on RFS ( $H R=1.003, p=0.009)$. No effect was determined in any of all the other parameters examined in the multivariate analysis (Table 5).

\section{Discussion}

In patients with primary ITP, when platelet count remains stable at $<30 \times 109 / \mathrm{L}$, treatment is needed to reduce the risk

Table 3. Comparison of parameters according to long-term response to splenectomy

\begin{tabular}{|c|c|c|c|}
\hline & $\begin{array}{l}\text { Patients with stable } \\
\text { response } \\
\text { (CR+PR) }(n=29)\end{array}$ & $\begin{array}{l}\text { Patients with recurrence and } \\
\text { no response (NR+relapse) } \\
(n=17)\end{array}$ & $\mathbf{p}$ \\
\hline Age at diagnosis (yrs) (Mean \pm SD) & $36.62 \pm 20.13$ & $29.53 \pm 17.87$ & 0.236 \\
\hline $\begin{array}{l}\text { Gender } \\
\text { Female } \\
\text { Male }\end{array}$ & $\begin{array}{l}20(69.0 \%) \\
9(31.0 \%)\end{array}$ & $\begin{array}{l}11(64.7 \%) \\
6(35.3 \%)\end{array}$ & 0.766 \\
\hline $\begin{array}{l}\text { Response to steroids } \\
\text { No response } \\
\text { Dependent }\end{array}$ & $\begin{array}{l}10(34.5 \%) \\
19(65.5 \%)\end{array}$ & $\begin{array}{l}8(47.1 \%) \\
9(52.9 \%)\end{array}$ & 0.533 \\
\hline $\begin{array}{l}\text { Immunosuppressive usage } \\
\text { No } \\
\text { Yes }\end{array}$ & $\begin{array}{l}23(79.3 \%) \\
6(20.7 \%)\end{array}$ & $\begin{array}{l}15(88.2 \%) \\
2(11.8 \%)\end{array}$ & 0.691 \\
\hline $\begin{array}{l}\text { Time from diagnosis to splenectomy (months) } \\
\text { (Mean } \pm \text { SD) }\end{array}$ & $10.5(0.5-392.6)$ & $13.5(0.0-133.9)$ & 0.955 \\
\hline Age at splenectomy (yrs) (Mean \pm SD) & $40.48 \pm 17.71$ & $32.59 \pm 15.71$ & 0.136 \\
\hline $\begin{array}{l}\text { At the time of diagnosis } \\
\text { Platelet count }(\times 109 / \mathrm{L}) \\
\text { PCT } \\
\text { MPV (fL) } \\
\text { Lymphocyte count }(\times 109 / \mathrm{L}) \\
\text { PLR } \\
\text { PDW } \\
\text { LDH }(/ \mathrm{I}) \\
\text { Vitamin } \mathrm{B} 12(\mathrm{pmol} / \mathrm{L}) \\
\text { Ferritin }(\mathrm{ng} / \mathrm{mL})\end{array}$ & $\begin{array}{l}8.0(1.0-43.0) \\
0.0(0.0-0.4) \\
8.5(4.7-19.0) \\
1.8(0.84-4.32) \\
5.9(0.7-16.8) \\
16.9(12.2-85.7) \\
222.1(136.0-488.0) \\
265.0(111.0-2000.0) \\
50.0(2.4-202.0)\end{array}$ & $\begin{array}{l}12.0(2.0-40.0) \\
0.0(0.0-0.1) \\
9.4(4.5-11.9) \\
2.47(1.4-5.1) \\
4.3(0.8-20.8) \\
16.3(12.1-60.3) \\
230.3(133.0-432.0) \\
275.0(143.0-1101.0) \\
55.4(2.2-225.0)\end{array}$ & $\begin{array}{l}0.516 \\
0.666 \\
0.909 \\
0.018 \\
0.674 \\
0.446 \\
0.387 \\
0.936 \\
0.828\end{array}$ \\
\hline
\end{tabular}




\begin{tabular}{|c|c|c|c|c|}
\hline & $\begin{array}{l}\text { Patients with stable } \\
\text { response }(n=29)\end{array}$ & $\begin{array}{l}\text { Patients with recurrence } \\
\text { and no response }(n=17)\end{array}$ & $\begin{array}{l}\text { Total } \\
(n=46)\end{array}$ & $\mathbf{p}$ \\
\hline \multicolumn{5}{|c|}{ Absolute lymphocyte count $\left(\times 10^{9} / \mathrm{L}\right)$} \\
\hline$\leq 1.85$ & $15(51.7 \%)$ & $3(17.6 \%)$ & $18(39.1 \%)$ & \multirow{2}{*}{0.031} \\
\hline$>1.85$ & $14(48.3 \%)$ & $14(82.4 \%)$ & $28(60.9 \%)$ & \\
\hline
\end{tabular}

\begin{tabular}{llll|}
\hline $\begin{array}{l}\text { Table 5. } \begin{array}{c}\text { Factors } \\
\text { (multivariate analysis) }\end{array} \\
\text { affecting }\end{array}$ & relapse-free & survival \\
& \multicolumn{3}{l}{ Relapse-free survival } \\
\cline { 2 - 4 } & HR & $\mathbf{9 5 \%}$ Cl & p \\
\hline Gender & 0.245 & $0.028-2.161$ & 0.205 \\
\hline Age at diagnosis & 1.316 & $0.666-2.600$ & 0.429 \\
\hline Lymphocyte count & 1.003 & $1.001-1.005$ & $\mathbf{0 . 0 0 9}$ \\
\hline Platelet count & 1.032 & $0.967-1.100$ & 0.342 \\
\hline PCT & 1.089 & $0.967-1.212$ & 0.122 \\
\hline MPV & 0.591 & $0.334-1.049$ & 0.072 \\
\hline Response to steroids & 0.091 & $0.003-2.737$ & 0.167 \\
\hline Age at splenectomy & 0.843 & $0.433-1.641$ & 0.616 \\
\hline $\begin{array}{l}\text { Time from diagnosis to } \\
\text { splenectomy }\end{array}$ & 1.010 & $0.927-1.101$ & 0.813 \\
\hline $\begin{array}{l}\text { MPV: Mean platelet volume, PCT: Plateletcrit, Cl: Confidence interval, HR: } \\
\text { Hazard ratio }\end{array}$ & & & \\
\hline
\end{tabular}

early relapse rate is high. It has been reported in literature that relapse rates were higher in the early years (9).

Several factors have been previously studied in respect of capability to predict $R$ to splenectomy. These studies have shown a young age $(3,9,11,12)$, pre-post high platelet count $(9,11-13)$, a good $R$ to steroids before splenectomy $(9,11,13)$, a short time from diagnosis to splenectomy $(3,9)$, and a high megakaryocyte count at the time of diagnosis (9) to be effective parameters in respect of a stable response. However, there is no universally accepted marker that has been shown by all. In contrast to those previous studies, the current study results showed that although the age at diagnosis and age at splenectomy were higher in patients with a stable response compared to those with NR and relapse, the difference was not statistically significant. The duration of disease in patients with a stable response was shorter than in patients with NR and the response to steroids before splenectomy was better but these differences were not statistically significant. In a meta-analysis of serious bleeding. While approximately $70-80 \%$ of patients respond to corticosteroid treatment, relapse is widespread. When various factors are taken into consideration such as the patient's history of bleeding, suitability for surgery, comorbidities, tolerance of side-effects, lifestyle and preferences, a choice can be made between more advanced medical treatments and splenectomy for patients who are steroid-resistant (6). Although splenectomy is used less often now than in the past due to the emergence of new drugs, it remains the standard second-line treatment for ITP patients unresponsive to corticosteroids $(1,3,4)$.

According to the results of this study, while a $R$ was obtained in $44(95.6 \%)$ of the total 46 patients in the first month after splenectomy, relapse developed in $15(34.0 \%)$ patients throughout the follow-up period. The median time to relapse was 61.9 months. In previous studies, the response to splenectomy in the early period was found to be $74 \%$ (8). An extremely high $\mathrm{R}$ rate was determined in the current study. However, as CR was obtained throughout the total follow-up period in 27 patients, the long-term response rate was determined as $58.6 \%$. Similar studies have also shown a cure rate of approximately $58-66 \%(9,10)$. In the current study, the 1, 3 and 5-year RFS rates were found to be $90.9 \%, 86.3 \%$ and $84.0 \%$, respectively. In a retrospective study that examined 54 ITP patients between 1999 and 2005, the 1, 3, and 5-year RFS rates were reported as $91.9 \%, 88.4 \%$ and $88.4 \%$, respectively (11). In 4 of the 6 patients with $\mathrm{PR}$, relapse developed within 1 year. This finding shows that when CR cannot be obtained after splenectomy, the that examined 135 cases published between 1996 and 2004, it was shown that none of 12 preoperative factors, including age and $R$ to steroids, were effective (10).

In the current study, when the impact of initial hematological and biochemical parameters was examined on response to splenectomy, a relationship was only found in ALC at the time of diagnosis. ALC in patients with a stable response was determined to be significantly lower than that of patients with NR or subsequent relapse $(p=0.018)$. Patients with initial ALC $\leq 1.85 \times 109 / L$ were observed to have a better response to splenectomy ( $p=0.031$ ). ALC at the time of diagnosis was seen to affect RFS in the Cox-Regression model applied according to the response to splenectomy ( $H R=1.003, p=0.009)$. None of the other parameters was seen to have any effect. In 4 studies of pediatric patients diagnosed with acute ITP, low baseline ALC or low lymphocyte count in the first months of the disease was shown to be significant risk factors in respect of future development of chronic ITP (1417). Another study of 209 adult ITP patients showed that low ALC at the time of diagnosis was an independent risk factor for the development of infection (18). In the only study having similar results to the current study, Culic et al. (19) reported that there was a negative correlation between ALC and platelet count at the time of diagnosis in ITP patients and high ALC could predict a poor prognosis. In all the studies mentioned, the parameters were not studied in respect of response to splenectomy. To the best of our knowledge, the current study is the first to have examined ALC in respect of response to splenectomy, and contrary to what has 
been previously known, patients with a low initial ALC were shown to have a good prognosis.

As a result of the activation of specific auto-reactive $\mathrm{T}$ lymphocytes, the production and proliferation of $\mathrm{B}$ lymphocytes producing antiplatelet antibodies is one of the most significant immunological impairments in ITP (20). In addition, impaired cellular immunity is thought to be important in the pathophysiology of ITP. There is current important evidence showing that generalized functional impairment of autoreactive $\mathrm{T}$ cells is a critical immunopathological cause of ITP and that antiplatelet autoantibodies are under the control of $\mathrm{T}$ cells (21). There are conflicting findings about the relationship of these immunological occurrences and lymphocyte count. Three significant points emerged from the results of an important study that considered lymphocyte counts: the rates of CD4+ cells in the peripheral blood of ITP patients were lower than those of the control group, CD8+ rates increased, and the CD4+/CD8+ ratio decreased. At the same time, the $B$ lymphocytes (CD19+) were shown to be significantly higher than in the control group (22). In our study, lymphocyte subgroup analysis should be performed in order to reach the above mentioned comments. This analysis could not be performed due to the design of the study. However, when the results of these studies are considered together with those of the current study, it can be speculated that high ALC originating from both $B$ and T cells in ITP patients impairs the immune response and could cause an increase in underlying autoantibody production leading to increase in relapse rates in the future. In contrast to these results, Yilmaz and Ayhan (20) showed that the percentages of $T$ lymphocytes, $T$ helper lymphocytes, regulatory $T$ lymphocytes and storage $B$ lymphocytes were initially significantly lower than those of the control group. However, at the end of the study, no difference was seen in these rates between patients who responded or did not respond to first stage treatment. In conclusion, it was reported that the percentages of regulatory $T$ lymphocytes and storage $B$ lymphocytes were not of any benefit in predicting the treatment outcomes of newly-diagnosed adult ITP patients.

There were some limitations to this study, primarily the retrospective design and smaller number of patients. However, we know that ITP is a rare disease in adults. Furthermore, the lack of lymphocyte subtype analysis and peripheral blood smear limited the interpretation and discussion of the current results.

\section{Conclusion}

Measurement of ALC at the time of diagnosis may be considered as predictive of the response to splenectomy. A low ALC at the time of diagnosis is a determining factor of a better response to splenectomy and higher RFS. Patients with a high initial ALC should be monitored more carefully and frequently. Even with splenectomy, there is a higher possibility of relapse and/or NR in this patient group. There is a need for further studies to analyze lymphocyte subgroups and the cytokine network to be able to clarify the underlying mechanisms.

\section{Ethics}

Ethics Committee Approval: The study was approved by University of Health Sciences Turkey, Ankara Diskapi Yildirim Beyazit Research and Training Hospital Ethics Committee (protocol no: 57/12, date: 17.12.2018).

Informed Consent: Retrospective study.

Peer-review: Externally peer-reviewed.

\section{Authorship Contributions}

Concept: A.Y., Ç.P., Design: A.Y., M.A., Data Collection or Processing: A.Y., O.S., H.B.A.Ö., A.K., Analysis or Interpretation: A.Y., Ç.P., Literature Search: M.A., S.M., P.C., Writing: A.Y.

Conflict of Interest: No conflict of interest was declared by the authors.

Financial Disclosure: The authors declared that this study received no financial support.

\section{References}

1. Kashiwagi H, Tomiyama $\mathrm{Y}$. Pathophysiology and management of primary immune thrombocytopenia. Int $\mathrm{J}$ Hematol. 2013;98:24-33.

2. Lucchini E, Fanin R, Cooper N, Zaja F. Management of immune thrombocytopenia in elderly patients. Eur J Intern Med. 2018;58:70-76.

3. Shojaiefard A, Mousavi SA, Faghihi SH, Abdollahzade S. Prediction of response to splenectomy in patients with idiopathic thrombocytopenic purpura. World J Surg. 2008;32:488-493.

4. Neunert C, Lim W, Crowther M, et al. The American Society of Hematology 2011 evidence-based practice guideline for immune thrombocytopenia. Blood. 2011;117:4190-4207.

5. Ghanima W, Godeau B, Cines DB, Bussel JB. How I treat immune thrombocytopenia: the choice between splenectomy or a medical therapy as a second-line treatment. Blood. 2012;120:960-969.

6. Stasi R, Newland A, Thornton P, Pabinger I. Should medical treatment options be exhausted before splenectomy is performed in adult ITP patients? A debate. Ann Hematol. 2010;89:1185-1195.

7. Rodeghiero F, Stasi R, Gernsheimer T, et al. Standardization of terminology, definitions and outcome criteria in immune thrombocytopenic purpura of adults and children: report from an international working group. Blood. 2009;113:23862393.

8. Pardhan A, Hameed A, Zafar H, Mazahir S, Murtaza G. Outcomes of splenectomy for idiopathic thrombocytopenic purpura in adults: a developing country perspective. J Park Med Assoc. 2014;64:1240-1243. 
9. Guan Y, Wang S, Xue F, et al. Long-term results of splenectomy in adult chronic immune thrombocytopenia. Eur J Haematol. 2017;98:235-241.

10. Kojouri K, Vesely SK, Terrell DR, George JN. Splenectomy for adult patients with idiopathic thrombocytopenic purpura: a systematic review to assess long-term platelet count responses, prediction of response, and surgical complications. Blood. 2004;104:2623-2634.

11. Liu EH, Dilip CK, Yeh TS, Wu JH, Jan YY, Chen MF. Longterm relapse-free rurvival rate and predictive factors of idiopathic thrombocytopenic purpura in adults undergoing splenectomy. Biomed J. 2013;36:23-27.

12. Navez J, Hubert C, Gigot JF, et al. Does the site of platelet sequestration predict the response to splenectomy in adult patients with immune thrombocytopenic purpura? Platelets. 2015;26:573-576.

13. Shrestha S, Pradhan GB, Shrestha R, Singh R. Study on responses after splenectomy for idiopathic thrombocytopenic purpura patients, Kathmandu, Nepal. Nepal Med Coll J. 2012;14:328-330.

14. Akbayram S, Karaman K, Dogan M, Ustyol L, Garipardic M, Oner AF. Initial Lymphocyte Count as Prognostic Indicator for Childhood Immune Thrombocytopenia. Indian J Hematol Blood Transfus. 2017;33:93-96.

15. Bahoush G, Motamedi D, Vossough P. Initial lymphocyte count in patients with acute immune thrombocytopenic purpura: Can it predict persistence of the disease? Minerva Pediatr. 2014.
16. Deel MD, Kong M, Cross KP, Bertolone SJ. Absolute lymphocyte counts as prognostic indicators for immune thrombocytopenia outcomes in children. Pediatr Blood Cancer. 2013;60:1967-1974.

17. Ahmed I, Rajpurkar M, Thomas R, Chitlur M. Initial lymphocyte count and the development of persistent/ chronic immune thrombocytopenic purpura. Pediatr Blood Cancer. 2010;55:508-511.

18. Hu MH, Yu YB, Huang YC, et al. Absolute lymphocyte count and risk of short-term infection in patients with immune thrombocytopenia. Ann Hematol. 2014;93:1023-1029.

19. Culic S, Labar B, Marusic A, Salamunic I. Correlations among age, cytokines, lymphocyte subtypes, and platelet counts in autoimmune thrombocytopenic purpura. Pediatr Blood Cancer. 2006;47(5 Suppl):671-674.

20. Yilmaz M, Ayhan S. Percentage of Memory B Lymphocytes and Regulatory T Lymphocytes in Peripheral Blood are Low but Not Predictive of Therapy outcomes in Newly Diagnosed Adult Patients with Primary Immune Thrombocytopenia. Indian J Hematol Blood Transfus. 2017;33:586-591.

21. Kuwana M, Ikeda Y. The role of autoreactive T-cells in the pathogenesis of idiopathic thrombocytopenic purpura. Int $\mathrm{J}$ Hematol. 2005;81:106-112.

22. Rong W, Yan-xiang Z, Shan-shan X, Ju-mei S. Lymphocyte subsets in primary immune thrombocytopenia. Blood Coagul Fibrinolysis. 2014;25:816-819. 